\title{
Correction to: Do We-Experiences \\ Require an Intentional Object? \\ On the Nature of Reflective \\ Communities (Following Gerda \\ Walther)
}

Sebastian Luft

Correction to:

Chapter "Do We-Experiences Require an Intentional

Object? On the Nature of Reflective Communities

(Following Gerda Walther)" in:

S. Luft and R. Hagengruber (eds.),

Women Phenomenologists on Social Ontology,

Women in the History of Philosophy and Sciences 1,

https://doi.org/10.1007/978-3-319-97861-1_10

The original version of the book was inadvertently published without the first paragraph in Chapter 10. The erratum chapter and the book have been updated with the change. 